\title{
The effect of iron on the expression levels of calcium related gene in cisplatin resistant epithelial ovarian cancer cells
}

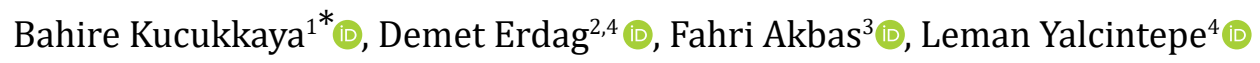 \\ ${ }^{1}$ Department of Biophysics, Faculty of Medicine, Istanbul Yeni Yuzyil University, 34010 Istanbul, Turkey \\ ${ }^{2}$ Department of Computer programming, Vocational School, Biruni University, 34010 Istanbul, Turkey \\ ${ }^{3}$ Department of Biophysics, Faculty of Medicine, Bezmialem Vakif University, 34093 Istanbul, Turkey \\ ${ }^{4}$ Department of Biophysics, Istanbul Faculty of Medicine, Istanbul University, 34093 Istanbul, Turkey
}

*Correspondence: Bahire Kucukkaya, Department of Biophysics, Faculty of Medicine, Istanbul Yeni Yuzyil University, Maltepe NBHD, No. 26 P.K. Yilanli Ayama street, 34010 Istanbul, Turkey. bahire.kucukkaya@yeniyuzyil.edu.tr

Academic Editor: Giovanni Blandino, Regina Elena Cancer Institute, Italy

Received: January 28, 2021 Accepted: June 14, 2021 Published: August 30, 2021

Cite this article: Kucukkaya B, Erdag D, Akbas F, Yalcintepe L. The effect of iron on the expression levels of calcium related gene in cisplatin resistant epithelial ovarian cancer cells. Explor Target Antitumor Ther. 2021;2:309-22. https://doi.org/10.37349/ etat.2021.00048

\begin{abstract}
Aim: Anticancer drugs (chemotherapeutics) used in cancer treatment (chemotherapy) lead to drug resistance. This study was conducted to investigate the possible effect of iron on calcium homeostasis in epithelial ovarian cancer cells (MDAH-2774) and cisplatin-resistant cells of the same cell line (MDAH-2774/DDP).

Methods: To develop MDAH-2774/DDP cells, MDAH-2774 (MDAH) cells were treated with cisplatin in dose increases of $5 \mu \mathrm{M}$ between $0 \mu \mathrm{M}$ and $70 \mu \mathrm{M}$. The effect of iron on the viability of MDAH and MDAH/DDP cells was determined by 3-(4,5-dimethylthiazol-2-yl)-2,5-diphenyltetrazolium bromide test at the end of $24 \mathrm{~h}$ incubation.

Results: At increasing iron concentrations in MDAH and MDAH/DDP cells, the mRNA gene of fifteen genes [inositol 1,4,5-triphosphate receptor $\left(I P_{3} R\right) 1 / 2 / 3$, ryanodine receptor $(R Y R) 1 / 2$, sarco/endoplasmic reticulum $\mathrm{Ca}^{2+}$ ATPase (SERCA)1/2/3, $\mathrm{Na}^{+} / \mathrm{Ca}^{2+}$ exchange (NCX)1/2/3, and plasma membrane $\mathrm{Ca}^{2+}$ ATPase (PMCA)1/2/3/4] associated with $\mathrm{Ca}^{2+}$ differences in expression were determined by quantitative reverse transcription-polymerase chain reaction. Changes in $I P_{3} R 2, R Y R 1, S E R C A 2, N C X 3, P M C A 1$, and PMCA3 gene expressions were observed in iron treatment of MDAH/DDP cells, while changes were detected in iron treatment of MDAH cells in $I P_{3} R 1 / 2 / 3, R Y R 1 / 2$, SERCA1/2/3, NCX2/3, and PMCA1 expressions.

Conclusions: This changes in the expression of calcium channels, pumps, and exchange proteins in the epithelial ovarian cancer cell line and in cisplatin-resistant epithelial ovarian cancer cells suggest that iron may have an important role in regulating calcium homeostasis. Due to differences in the expression of genes that play of an important role in the regulation of calcium homeostasis in the effect of iron, drug resistance can be prevented by introducing a new perspective on the use of inhibitors and activators of these genes and thus cytostatic treatment strategies.
\end{abstract}




\section{Keywords}

Cisplatin, drug resistance, calcium, iron, inositol 1,4,5-triphosphate receptor, ryanodine receptor, sarco/ endoplasmic reticulum $\mathrm{Ca}^{2+}$ ATPase, $\mathrm{Na}^{+} / \mathrm{Ca}^{2+}$ exchange

\section{Introduction}

Cancer is an important health problem affecting many people around the world. For this reason, great interest and economic effort is spent to discover new strategies and methods for the prevention and treatment of cancers worldwide [1]. Although chemotherapy is the main strategy in cancer treatment, drug resistance to chemotherapeutic drugs is one of the reasons that hinder success. While many cancers initially show sensitivity to chemotherapy, drug resistance appears over time in the effectiveness of various mechanisms. Clinically, drug resistance may be present before treatment (internal) or develop as a result of treatment (acquired) [2]. Deaths of among women worldwide result from ovarian cancer which is one of the ten most prevalent types of cancer. Epithelial tumor cancer account for $75 \%$ of all ovarian cancers and is the most common ovarian cancer [3].

Iron and calcium are the essential elements in the fulfillment of vital functions of cells. Calcium is a secondary messenger associated with basic physiological role, such as cell viability, migration, cycle control, apoptosis, and gene expression [4]. Most cellular events are controlled by intracellular calcium ion $\left(\left[\mathrm{Ca}^{2+}\right]_{\mathrm{i}}\right)$. The intracellular $\mathrm{Ca}^{2+}$ concentration is kept at very low levels $\left(\sim 10^{-7} \mathrm{~mol} / \mathrm{L}\right)$, but the release of a very small amount of $\mathrm{Ca}^{2+}$ from the intracellular organelles $\left(\sim 10^{-5} \mathrm{~mol} / \mathrm{L}\right)$ or the flow of $\mathrm{Ca}^{2+}$ into the cell from outside $\left(\sim 10^{-5} \mathrm{~mol} / \mathrm{L}\right)$ the cell can generate important signals by activating the signal transduction cascades in the cell [5]. In general, opening of permeable ion channels to $\mathrm{Ca}^{2+}$ increases $\left[\mathrm{Ca}^{2+}\right]_{i}$, while active $\mathrm{Ca}^{2+}$ carriers are responsible for returning $\left[\mathrm{Ca}^{2+}\right]_{i}$ to rest. Intracellular $\mathrm{Ca}^{2+}$ homeostasis is regulated through diverse calcium channels, pumps and exchange proteins. In non-excitable cells, ER is the main organelles that store $\mathrm{Ca}^{2+}$ in the cell, and the channels that give $\mathrm{Ca}^{2+}$ from these organelles into the cell; inositol 1,4,5-triphosphate receptors $\left(I P_{3} R s\right)$ and ryanodine receptors (RYRs) [6]. RYRs are mainly found in cells that can be stimulated, while $I P_{3} R s$ are found in cells that cannot be stimulated. So far, 3 types of $I P_{3}$ receptors as $I P_{3} R 1, I P_{3} R 2$ and $I P_{3} R 3$ have been defined [4]. Stimuli that belong to different stress elements (e.g., immobilization stress, oxidative stress, and hypoxia) as well as apoptosis may modulate $I P_{3} R s$. Expression of $\mathrm{IP}_{3} \mathrm{Rs}$ may be increased or decreased relying on the length and strength of the stress stimuli [7].

RYRs have three isoforms in mammals as RYR1, RYR2, and RYR3. RYR1 is mainly found in skeletal muscle, while $R Y R 2$ is found in cardiac muscle. $R Y R 3$ is mostly found in the thalamus, hippocampus, corpus striatum and smooth muscle. In addition, RYR3 is found in mammalian skeletal muscle cells during development [5]. Another $\mathrm{Ca}^{2+}$ pump in the endo/sarcoplasmic reticulum (ER/SR) membrane is sarco/endoplasmic reticulum $\mathrm{Ca}^{2+}$ ATPase (SERCA). This pump helps to regulate the concentration of cytologic $\mathrm{Ca}^{2+}$ by pumping the calcium directly out of the cell or organelles [8, 9]. In addition, plasma membrane $\mathrm{Ca}^{2+}$ ATPase (PMCA) pump in the eukaryotic cell membranes conduce to the regulation of cytoplasmic $\mathrm{Ca}^{2+}$ concentration by removing the excess $\mathrm{Ca}^{2+}$ in the cell. $\mathrm{Na}^{+} / \mathrm{Ca}^{2+}$ exchange (NCX) proteins remove $\mathrm{Ca}^{2+}$ from the cell to maintain cellular homeostasis. Ion channels were shown to act as the main regulators of specific pathways associated with proliferation, migration, or survival in the progression of cancer and also play a role in different types of cancer such as colon, prostate and breast cancer [4].

Iron is an essential trace element and is the most plenty transition metal in the human body. Because of iron's ability to receive and donate electrons, it is a crucial component of storage and transport molecules and enzymes involved in energy production and intermediate metabolism when converting between iron $\left(\mathrm{Fe}^{3+}\right)$ and iron $\left(\mathrm{Fe}^{2+}\right)$ oxidation states. Since the ribonucleotide reductase (RR) enzyme, which is responsible for the synthesis of deoxyribonucleotides, is iron-dependent, it is vital in the process of iron cell division [10]. It has also been shown that iron availability regulates other proteins involved in DNA damage detection by modulating the cell cycle, such as murine double minute 2 (Mdm2), growth arrest and DNA damage (GADD45) and p21/WAF1. In addition, iron is the functional component of proteins containing heme and iron-sulfur cluster synthesized in mitochondria. Therefore, iron is an important element for survival, growth, and differentiation of cell [10]. Furthermore, changes are expected in iron metabolism 
in the tumor cells, which generally have rapid growth rates. Iron homeostasis is very well regulated in the metabolism [2]. The excess or deficiency of iron causes formation of reactive oxygen species (ROS) in the organism and the organism is damaged [2]. The formation of ROS and especially reactive hydroxyl radicals through Fenton reaction causes mutations and severe cellular damage. As a result of these reactions, studies on iron metabolism in cancer cells have shown that tumor cells require higher iron concentrations, and iron uptake protein genes have been shown to be highly expressed [2]. However, the studies are limited on general iron metabolism in drug-resistant tumor cells. In this research, we examined the effect of iron on the gene expression of major channels $\left(I P_{3} R 1 / 2 / 3, R Y R 1\right.$, and RYR2), pumps (SERCA1/2/3, PMCA1/2/3, and $P M C A 4)$, and exchangers (NCX1/2, and NCX3) involved in the calcium regulation process in ovarian cancer cells and cisplatin resistant ovarian cancer cells. Iron was noted to indicate differential effects on the studied genes with a concentration-independent activity. To cope with drug resistance, defining the modelling $\mathrm{Ca}^{2+}$ channels/transporters/exchangers can supply a promising chemotherapy for cancer resistance.

In this study, epithelial ovarian cancer (EOC) cells and the same cell line resistant to cisplatin, fifteen calcium-associated genes $\left(I P_{3} R 1 / 2 / 3, R Y R 1 / 2\right.$, SERCA1/2/3, NCX1/2/3, and PMCA1/2/3/4) expressions were examined using the quantitative reverse transcription-polymerase chain reaction (RT-PCR) method.

\section{Materials and methods}

\section{Cell line and chemicals}

Human EOC cell line, MDAH cells were obtained from the Department of Biophysics in Istanbul Faculty of Medicine and maintained in Dulbecco's modified Eagles medium (DMEM) F-12 supplemented with 10\% heat-inactivated fetal calf serum (FCS), and $100 \mathrm{IU} / \mathrm{mL}$ penicillin-streptomycin. Incubation conditions at $37^{\circ} \mathrm{C}$ in a humidified atmosphere of $5 \% \mathrm{CO}_{2}$ were maintained in a Heraeus incubator (Hanau, Germany). Cisplatin (Sigma) was applied to the MDAH cell line with dose increments. The subline resistant to cisplatin (MDAH/DDP) from parental MDAH cell line was developed by increasing the $5 \mu \mathrm{M}$ dose, stepwise, $5 \mu \mathrm{M}$ to $70 \mu \mathrm{M}$ for cisplatin. Before the dose increments, adapted cells became confluent in respective drug concentrations and maintained at least for three weeks (approximately 3-4 weeks). Cells selected in $25 \mu \mathrm{M}$ cisplatin were maintained in medium with $25 \mu \mathrm{M}$ cisplatin for assays [11].

\section{3-(4,5-dimethylthiazol-2-yl)-2,5-diphenyltetrazolium bromide assay}

Cell viability was evaluated using 3-(4,5-dimethylthiazol-2-yl)-2,5-diphenyltetrazolium bromide (MTT) cell staining [12]. MDAH and MDAH/DDP groups were added to 96-well plates in triplicate in each well and $2 \times 10^{5}$ cells were incubated at $37^{\circ} \mathrm{C}$ for $24 \mathrm{~h}$. In DMEM containing $10 \%$ FCS, the MDAH/DDP group was prepared using various iron concentrations (from $0 \mu \mathrm{M}$ to $80 \mu \mathrm{M}$ ) for $24 \mathrm{~h}$ at $37^{\circ} \mathrm{C}$. MTT solution was added to the cells that was treated with iron. The experiment was incubated at $37^{\circ} \mathrm{C}$ for $30 \mathrm{~min}$ and $4 \mathrm{~h}$. Dimethyl sulfoxide (DMSO, $100 \mu \mathrm{L}$ ) was added to each well after removal of medium. Absorbance values were measured at $570 \mathrm{~nm}$ wavelength and the relative cell viability (\%) was expressed as a percentage relative to the untreated control cells.

\section{RNA isolation and real-time quantitative RT-PCR}

For isolation of total RNA, MDAH and MDAH/DDP cells were grown in four wells for each process, and total RNA was isolated using the total RNA extraction kit (Thermo). cDNA was synthesized from RNA (500 ng) using the Revert Aid First Strand cDNA synthesis kit (Thermo Scientific), according to the manufacturer's instructions. RT-PCR was performed using $I P_{3} R 1 / 2 / 3, R Y R 1 / 2, S E R C A 1 / 2 / 3, N C X 1 / 2 / 3$ and $P M C A 1 / 2 / 3$ and PMCA4-specific primers (Table 1). The original PCR primers were designed using primer 3 software (http:// primer3plus.com/). Primer sequences of genes are shown below (Table 1). Quantitative assays were tested with SYBR Green Master Mix (Thermo). The reaction mixture was prepared in a total volume of $20 \mu \mathrm{L}$. PCR conditions were performed at $95^{\circ} \mathrm{C}$ for $3 \mathrm{~min}$, then 40 cycles at $95^{\circ} \mathrm{C}$ for $10 \mathrm{~s}$ and $60^{\circ} \mathrm{C}$ for $30 \mathrm{~s}$. The target mRNA amount in the samples was calculated by normalizing according to the actin $\beta$-mRNA level. Each reaction was performed three times and mean values were determined. The transcriptional gene expression, which was later called gene expression, was changed to ethanol-treated controls as fold change (FC) and was defined by the $\Delta \Delta$ Ct method [13]. 
Table 1. Primary sequences of genes

\begin{tabular}{|c|c|c|}
\hline Common name & Primary couples (5'-3') & Product size (bp) \\
\hline$I P_{3} R I$ & $\begin{array}{l}\text { Forward: TGACGAGAACCTGCCCTAT } \\
\text { Reverse: TCCTTTCGCCATCTTGCT }\end{array}$ & 304 \\
\hline$I P_{3} R 2$ & $\begin{array}{l}\text { Forward: GCAATCGTGTCTGTTCCA } \\
\text { Reverse: TCTTCAAGTCTCAGCATCG }\end{array}$ & 332 \\
\hline$I P_{3} R 3$ & $\begin{array}{l}\text { Forward: GCCTACTATGAGAACCACACG } \\
\text { Reverse: CAGAAGAGCAATGAGATGAGAG }\end{array}$ & 389 \\
\hline$R Y R I$ & $\begin{array}{l}\text { Forward: TGACTACCATCAGCACGACA } \\
\text { Reverse: ACGAAGACGGCAGGAAATA }\end{array}$ & 297 \\
\hline RYR2 & $\begin{array}{l}\text { Forward: AACAAGTACATGCCTGGTTTGC } \\
\text { Reverse: TTGTTCTCATCAGGGAACAGGG }\end{array}$ & 348 \\
\hline SERCAI & $\begin{array}{l}\text { Forward: GTGATCCGCCAGCTAATG } \\
\text { Reverse: CGAATGTCAGGTCCGTCT }\end{array}$ & 361 \\
\hline SERCA2 & $\begin{array}{l}\text { Forward: CGCTACCTCATCTCGTCCA } \\
\text { Reverse: TCGGGTATGGGGATTCAA }\end{array}$ & 406 \\
\hline SERCA3 & $\begin{array}{l}\text { Forward: GATGGAGTGAACGACGCA } \\
\text { Reverse: CCAGGTATCGGAAGAAGAG }\end{array}$ & 409 \\
\hline$N C X 1$ & $\begin{array}{l}\text { Forward: GTCGCACTTGGAACATCA } \\
\text { Reverse: CCAGGGAGGAGAAGAAAA }\end{array}$ & 373 \\
\hline NCX2 & $\begin{array}{l}\text { Forward: CGGTGGATAAACTCATCAAGAA } \\
\text { Reverse: CAGGGCAACGAAGACAACA }\end{array}$ & 359 \\
\hline NCX3 & $\begin{array}{l}\text { Forward: GAGATGGGAAAGCCAGTAT } \\
\text { Reverse: ATGCCACGAAAACAACAG }\end{array}$ & 430 \\
\hline PMCA1 & $\begin{array}{l}\text { Forward: GAGATGGGAAAGCCAGTAT } \\
\text { Reverse: ATGCCACGAAAACAACAG }\end{array}$ & 418 \\
\hline PMCA2 & $\begin{array}{l}\text { Forward: GAGATGGGAAAGCCAGTAT } \\
\text { Reverse: ATGCCACGAAAACAACAG }\end{array}$ & 214 \\
\hline PMCA3 & $\begin{array}{l}\text { Forward: TGGTCCTCTACTTTGTGATTG } \\
\text { Reverse: TGGTGGTATAGGCACTGTTG }\end{array}$ & 417 \\
\hline PMCA4 & $\begin{array}{l}\text { Forward: CTGTGCGTAATGAAGTGC } \\
\text { Reverse: AGTCCCGGTAAGCTATG }\end{array}$ & 279 \\
\hline
\end{tabular}

\section{Statistical analysis}

Data were given as mean with standard deviation; at least 3 replicates were performed for each experimental set up. The statistical significance between control condition and each of the exposure samples were obtained with Student's $t$-test. Data were expressed as mean \pm standard error of the mean (SEM).

\section{Results}

Iron treatment of cells

MDAH and MDAH/DDP cells were incubated with iron for $24 \mathrm{~h}$ at increasing concentrations of iron. Iron was statistically determined to have no effect on the viability of MDAH and MDAH/DDP cells with the MTT test (Figure 1).

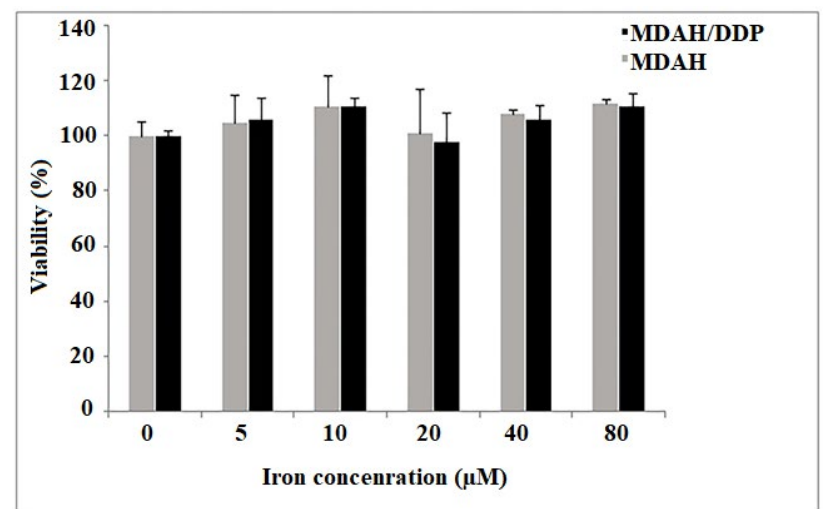

Figure 1. The viability of MDAH and MDAH/DDP cells after treatment with iron for $24 \mathrm{~h}$ was determined by performing the MTT test as described in the Materials and Methods section. Values were results from three independent experiments. Student's " $t$-test" was done 


\section{Expression of $\mathrm{Ca}^{2+}$ related genes}

Differences in mRNA expression of fifteen genes $\left(I P_{3} R 1 / 2 / 3, R Y R 1 / 2, S E R C A 1 / 2 / 3, N C X 1 / 2 / 3\right.$, and $P M C A 1 / 2 / 3 / 4$ ) associated with $\mathrm{Ca}^{2+}$ were analyzed by quantitative RT-PCR in increasing iron concentrations in MDAH and MDAH/DDP cells. 2- $\Delta \Delta \mathrm{Ct}$ values that were calculated from the measurement of $\mathrm{Ca}^{2+}$-related mRNA expressions from MDAH and MDAH/DDP cells were compared. A two-fold gene expression difference $(P<0.05)$ was taken as the cut-off level. At increasing iron concentrations in MDAH and MDAH/DDP cells, mRNA expression levels of $I P_{3} R 1 / 2 / 3, R Y R 1$ and $R Y R 2 \mathrm{Ca}^{2+}$ channels in the ER and releasing $\mathrm{Ca}^{2+}$ out of the cell were compared (Figure 2).
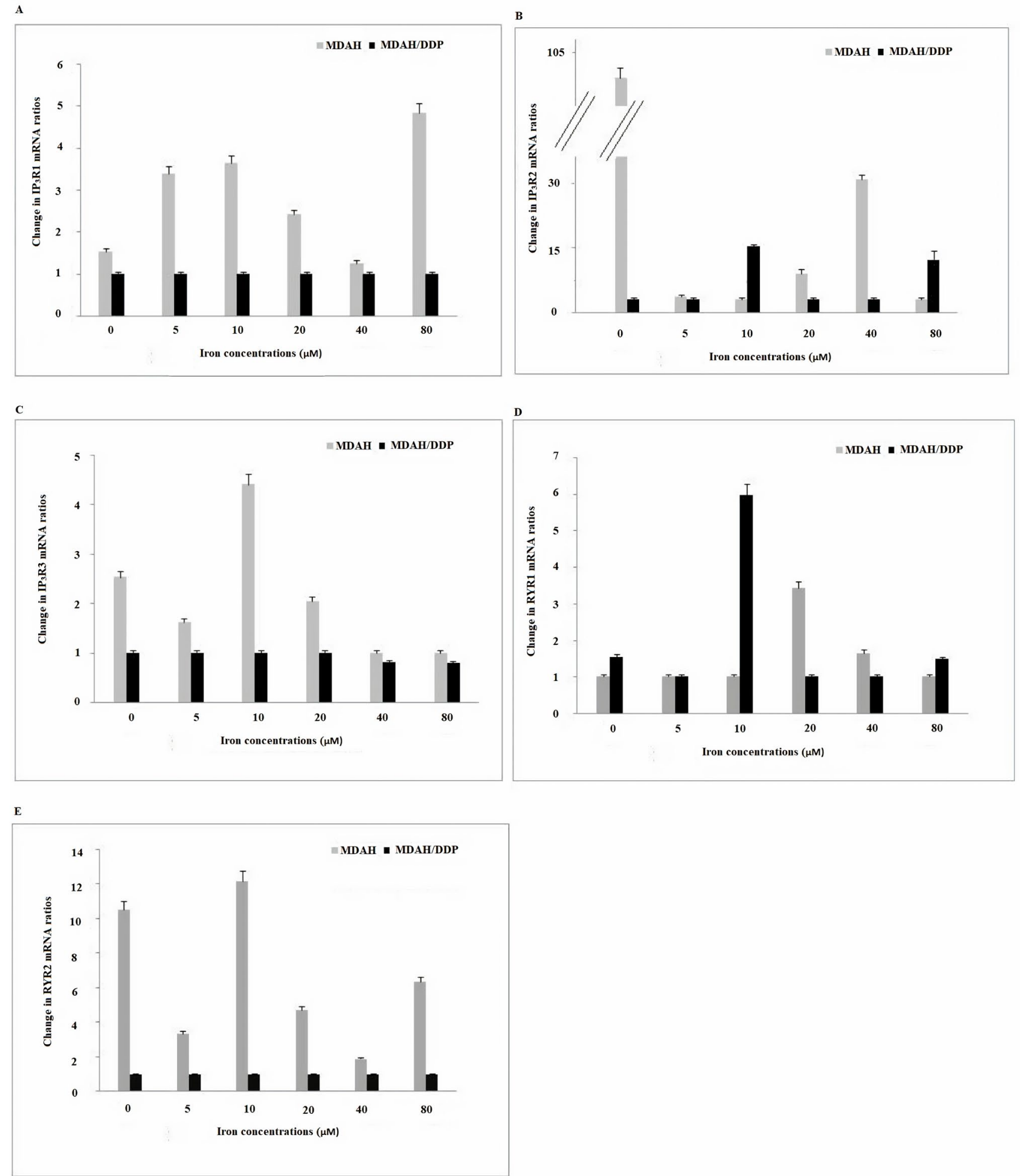

Figure 2. Gene expression of the IP3R1/2/3, RYR1 and $R Y R 2 \mathrm{Ca}^{2+}$ channels in the ER in MDAH and MDAH/DDP cells treated with increasing iron concentrations. The levels of change in mRNA gene expression rates for each sample were determined with respect to actin by RT-PCR method. A: IP3R1; B: IP3R2; C: IP3R3; D: RYR1; E: RYR2 
While no change in $I P_{3} R 1$ gene expression was observed in increasing concentrations of iron in MDAH/ DDP cells, a significant rise in $I P_{3} R 1$ gene expression was observed in the treatment of MDAH cells with $5 \mu \mathrm{M}, 10 \mu \mathrm{M}$ and $80 \mu \mathrm{M}$ iron. While an increase in $I P_{3} R 2$ gene expression was determined in the treatment of MDAH/DDP cells with $10 \mu \mathrm{M}$ and $80 \mu \mathrm{M}$ iron, a significant reduction in iron expression and $I P_{3} R 2$ gene expression was determined in MDAH cells. In addition, $I P_{3} R 2 \mathrm{mRNA}$ level was seen to be significantly higher in MDAH cells than other $I P_{3} R 1$ mRNA and $I P_{3} R 3$ mRNA expression levels. There is no change in $I P_{3} R 3$ gene expression determined in increasing concentrations of iron in MDAH/DDP cells, but an increase in $I P_{3} R 3$ gene expression was determined in the treatment of MDAH cells with 5, 10 and $20 \mu \mathrm{M}$ iron (Figure 2).

While an increase in RYR1 gene expression was observed at $10 \mu \mathrm{M}$ iron concentration of MDAH/DDP cells in iron treatment of MDAH/DDP and MDAH cells, a significant increase in $20 \mu \mathrm{M}$ iron treatment of MDAH cells and later decrease in both cell groups were detected. On the other hand, no change was observed in $R Y R 2$ gene expression in iron treatment of MDAH/DDP cells, while a decrease in RYR2 mRNA expression in MDAH cells at $5 \mu \mathrm{M}, 20 \mu \mathrm{M}$ and $40 \mu \mathrm{M}$ was observed. In addition, the examination of the gene expression levels of RYRs in MDAH and MDAH/DDP cells, showed that the level of RYR2 mRNA expression was quite lower in MDAH/DDP cells compared to expression in MDAH cells.

Thapsigargin sensitive SERCAs are responsible for the conservation and regeneration of agonist sensitive internal stores. No change in SERCA1 mRNA gene expression was observed in the treatment of $\mathrm{MDAH} / \mathrm{DDP}$ cells with increasing concentrations of iron, while an increase in MDAH cells was determined at $10 \mu \mathrm{M}$ (Figure 3). As a result of the treatment of MDAH/DDP and MDAH cells with increasing iron concentrations, a decrease in SERCA2 gene expression was determined in the treatment of MDAH/DDP cells with 5, 40 and $80 \mu \mathrm{M}$ iron. However, when SERCA2 mRNA gene expression was examined in non-iron treated MDAH and MDAH/DDP cells, it was found lower in MDAH/DDP cells. In addition, a significant rise in SERCA3 gene expression was determined in MDAH cells in increasing iron concentrations, while no change was detected in MDAH/DDP cells.
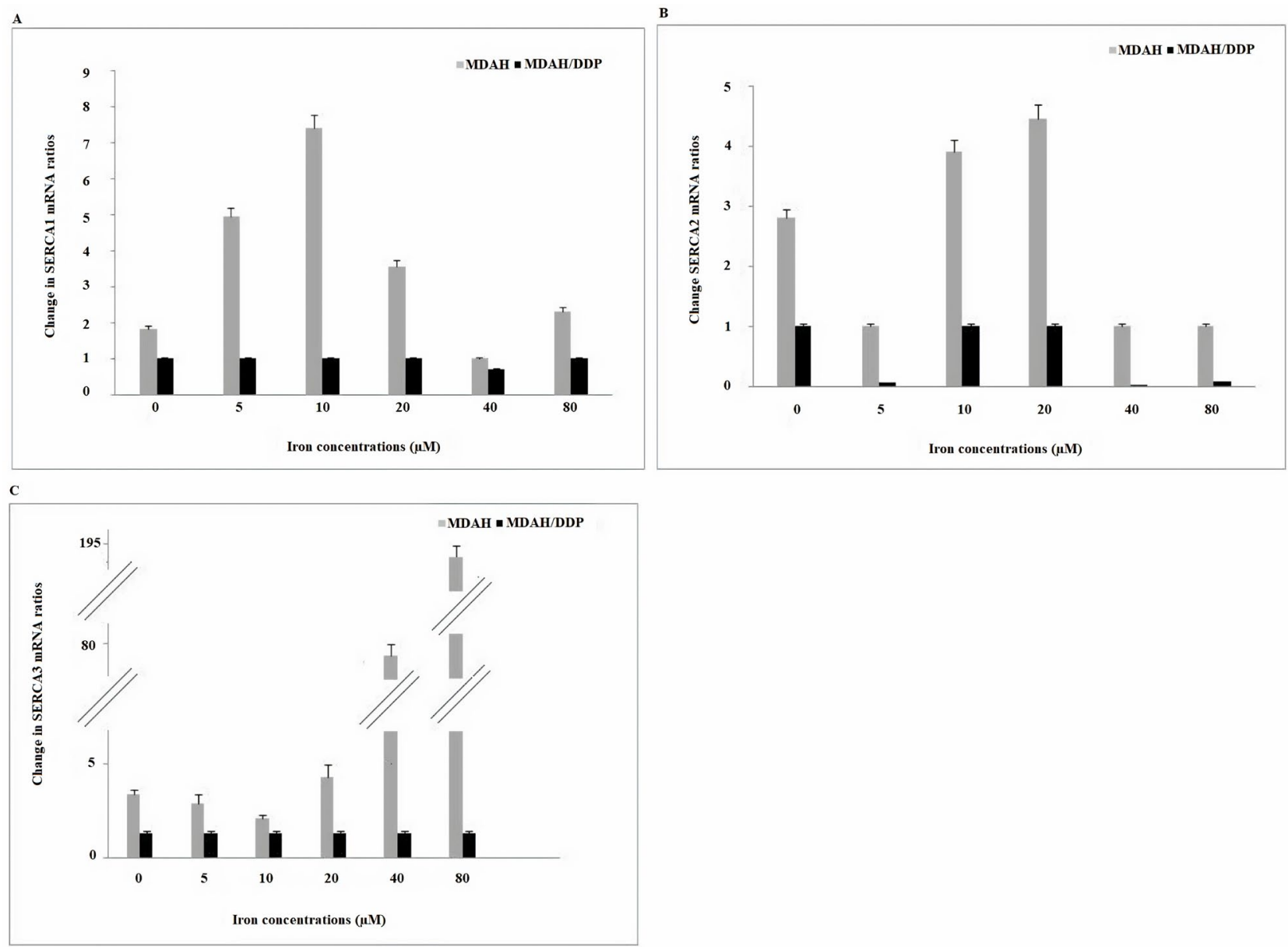

Figure 3. Gene expression of SERCA1/2 and SERCA3 $\mathrm{Ca}^{2+}$ pumps in the ER at increasing iron concentrations in MDAH and MDAH/DDP cells. The levels of change in mRNA expression rates for each sample were determined with respect to actin by RT-PCR method. A: SERCA1; B: SERCA2; C: SERCA3 
NCX proteins send $\mathrm{Ca}^{2+}$ into cytosol or organelle using the electrochemical gradient of $\mathrm{Na}^{+}$. When $N C X 1$ mRNA expressions in increasing iron concentrations of MDAH/DDP and MDAH cells were examined, no significant change was observed in both cell groups (Figure 4). While no change in NCX2 gene expression was observed in increasing concentrations of iron of MDAH/DDP cells, an increase in NCX2 mRNA expression in MDAH cells was determined in the treatment of MDAH cells with $10 \mu \mathrm{M}, 40 \mu \mathrm{M}$ and $80 \mu \mathrm{M}$ iron. In the treatment of MDAH/DDP cells with $5 \mu \mathrm{M}$ and $20 \mu \mathrm{M}$ iron, a decrease in NCX3 gene expression was detected, while an increase in NCX3 mRNA gene expression was determined in the treatment of MDAH cells with $5 \mu \mathrm{M}$ iron.
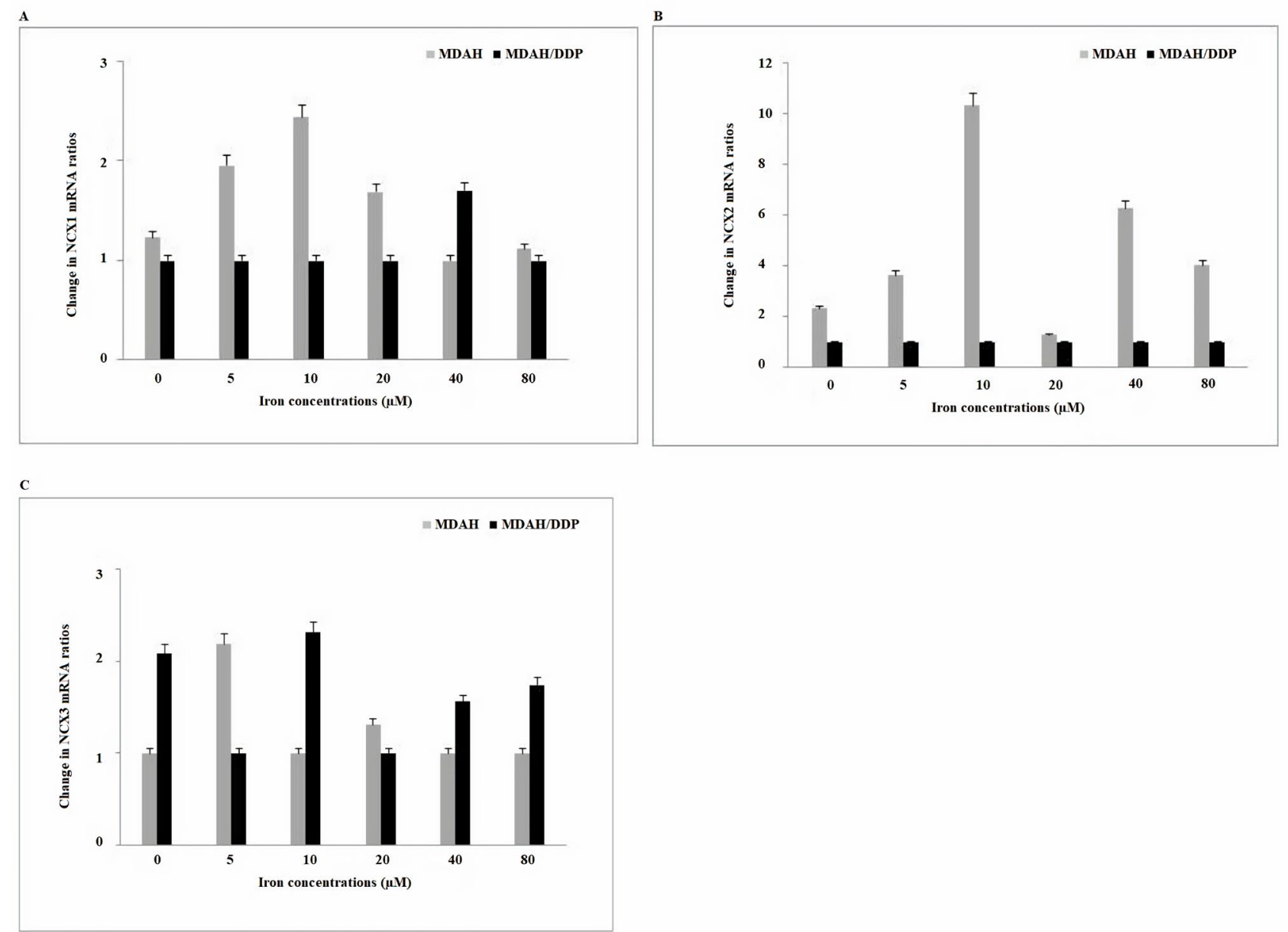

Figure 4. Gene expressions of $N C X 1 / 2$ and $N C X 3 \mathrm{Ca}^{2+}$ exchange carriers found in plasma and nuclear membrane at increasing iron concentrations in MDAH and MDAH/DDP cells. The levels of change in mRNA expression rates for each sample were determined with respect to $\beta$-actin by RT-PCR method. A: NCX1; B: NCX2; C: NCX3

$P M C A$ is the $\mathrm{Ca}^{2+}$ channel protein responsible for keeping the intracellular critical $\mathrm{Ca}^{2+}$ concentration low. A significant increase in PMCA1 gene expression was detected in the treatment of MDAH/DDP cells with $10 \mu \mathrm{M}$ and $20 \mu \mathrm{M}$ iron (Figure 5). However, an increase in PMCA1 gene expression was detected in the treatment of MDAH cells with $5 \mu \mathrm{M}$ and $80 \mu \mathrm{M}$ iron. An increase in PMCA3 expression was determined in the treatment of MDAH/DDP cells with $5 \mu \mathrm{M}, 40 \mu \mathrm{M}$ and $80 \mu \mathrm{M}$ iron, while no significant change was detected in the expression of PMCA3 in the treatment of MDAH cells with iron. No change in PMCA4 gene expression levels was observed in increasing iron concentrations of MDAH/DDP and MDAH cells. No change in PMCA2 mRNA gene expression was observed when MDAH and MDAH/DDP cells were treated with iron. 

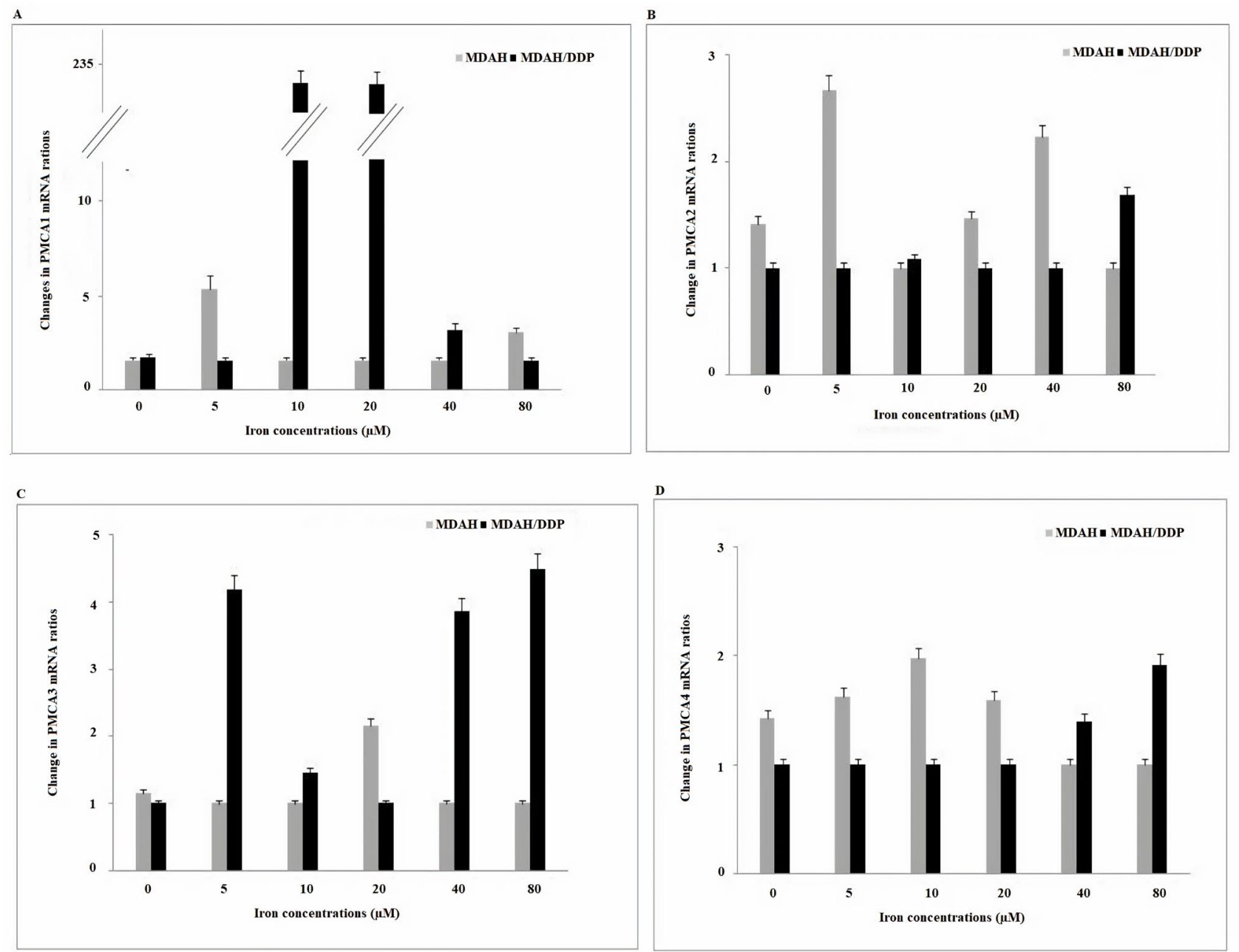

Figure 5. Gene expression of $P M C A 1 / 2 / 3$ and PMCA4 channels in the plasma membrane at increasing iron concentrations in MDAH and MDAH/DDP cells. The levels of change in mRNA gene expression rates for each sample were determined with respect to P-actin by RT-PCR method. A: PMCA1; B: PMCA2; C: PMCA3; D: PMCA4

\section{Discussion}

Cisplatin is one of the most effective anticancer agents known as cisplatinum or cis-diamminedichloroplatin (II). It has been widely used for the treatment of different types of neoplasms, including head, neck, lung, ovarian, breast, brain, kidney and testicular cancers, and leukemia. In general, cisplatin and other platinum-based compounds are considered cytotoxic drugs that inhibit DNA synthesis and mitosis, killing cancer cells and causing apoptotic cell death. It is characterized by the effect of various molecular mechanisms, production of ROS and lipid peroxidation, stimulation of p53 signaling, and cell cycle arrest, down regulation of proto-oncogenes, anti-apoptotic proteins, and oxidative stress in both internal and external pathways in apoptosis [14]. However, cisplatin chemotherapy also causes important side effects such as hepatotoxic, nephrotoxic, cardiotoxic, neurotoxic and/or hematotoxic damage. In addition, cisplatin resistance may develop, and cancer may relapse in the treatment of some patients with cisplatin [15]. Therefore, cisplatin resistance is a major barrier to successful treatment outcomes and limits its clinical application. Although cisplatin and its derivatives cause various side effects and resistance development in ovarian cancer, they are used in basic therapy. Cisplatin is used with other chemical agents or compounds to overcome barriers to the treatment of ovarian cancer with cisplatin. Therefore, it is very important to explain the resistance mechanism, and the mechanism of action of cisplatin is unknown. In this study, MDAH/DDP cells were treated with increasing iron concentrations to investigate the effect of iron on calcium channels, carriers, and exchange proteins of mRNA gene expressions in ovarian cells in which ovarian cancers developed cisplatin resistance, and 15 genes $\left(I P_{3} R 1 / 2 / 3, R Y R 1 / 2, S E R C A 1 / 2 / 3, N C X 1 / 2 / 3, P M C A 1 / 2 / 3 / 4\right)$ related to $\mathrm{Ca}^{2+}$ were examined by quantitative RT-PCR method and compared with MDAH cells. 
The ER acts as the main $\mathrm{Ca}^{2+}$ storage in the cell. It is also the organelle that regulates ER cell apoptosis, survival, and ATP production. Intracellular $\mathrm{Ca}^{2+}$ levels are controlled by $\mathrm{Ca}^{2+}$ release from ER and $\mathrm{Ca}^{2+}$ entry from outside the cell. When calcium arrived the cytoplasm, $\mathrm{Ca}^{2+}$ often occurs complexes with calmodulin to regulate a diversity of kinases and cyclins, which regulate cell proliferation and apoptosis. [16, 17]. $\mathrm{Ca}^{2+}$ is a regulater for global cellular processes in such a way that any disturbances to $\mathrm{Ca}^{2+}$ homeostasis via changings in expression of $\mathrm{Ca}^{2+}$ channels and $\mathrm{Ca}^{2+}$ binding proteins can disrupt the cell-cycle [18]. $\mathrm{Ca}^{2+}$ levels of cytosolic the activity of guanosine exchange factor (GEF), a Ras stimulator, and GTPase activating protein (GAP), a Ras inhibitor. When GEF is activated, Ras stimulates the proliferative mitogen-activated protein kinase (MAPK) pathway. This results in upregulation of cyclin D1 in the cytoplasm and phosphorylation of RB1 and then, release of the E2F transcription factor which initiates the cells transition into S-phase. This relationship between calcium and RB1 show that elevated cytosolic $\mathrm{Ca}^{2+}$ levels can regulate activation of the MAPK pathway, causing removal of the G1/S transition. The first stage in metastasis is the loss of cell-cell connections. Focal adhesion kinase (FAK) is a protein tyrosine kinase that increases turnover of cell-cell contacts [19]. FAK is overexpressed in a number of tumors and is a significant indicator of patient survival. Rised intracellular $\mathrm{Ca}^{2+}$ upregulates FAK at focal adhesions through phosphorylation by the calmodulin-dependent protein kinase II (CaMKII) [20]. Thus, abnormal signaling resulting in increased intracellular $\mathrm{Ca}^{2+}$ levels can lead to a raise in FAK and a higher turnover rate for cell-cell attachments [21].

Under normal conditions, intracellular $\mathrm{Ca}^{2+}$ stimulates cell survival; however, increased $\mathrm{Ca}^{2+}$ levels under the influence of stimuli such as cisplatin and thapsigargin may trigger apoptosis. The release of $\mathrm{Ca}^{2+}$ from ER into the cell takes place by the channels of two different classes, $I P_{3} R s$ and $R Y R s$ [15]. Luminal ER Ca ${ }^{2+}$ levels are protected with SERCA (SERCA1/2/3) calcium pumps [22]. The activation of phospholipase C-coupled receptors (some G-protein coupled receptors) causes $\mathrm{IP}_{3}$ formation and then the release of $\mathrm{Ca}^{2+}$ from calciumsensitive channels $\left(I P_{3} R 1, I P_{3} R 2, I P_{3} R 3\right)$ in the ER membrane [23]. The cytosolic calcium signal induced by $I P_{3}$ is highly dependent on the expression profile of $I P_{3} R$ and the sensitivity of $I P_{3} R$ subtypes to $I P_{3}$ is also different [24]. In addition, $I P_{3} R$ regulates cellular functions such as secretion, motion, and autophagy [23]. Gene expression of $I P_{3} R$ has been shown to decrease in cancer and especially $I P_{3} R 3$ isoform in glioblastoma, gastric, small, and non-small lung, and colorectal cancer [25]. In addition, $I P_{3} R$ may play a role in cancer progression and metastasis, but its mechanism of action has not been revealed [25]. In our study, no change in $I P_{3} R 1$ and $I P_{3} R 3$ mRNA gene expression was observed in iron treatment of MDAH/DDP cells. However, an increase in the $I P_{3} R 1$ mRNA level was observed in iron treatment of MDAH cells, while a decrease in the $I P_{3} R 3$ mRNA level was determined. An increase in $I P_{3} R 2$ gene expression was determined in iron treatment of MDAH/DDP cells while a significant reduction in iron treatment of MDAH cells was determined. In addition, the comparison of MDAH/DDP cells and MDAH cells without iron conditions showed that $I P_{3} R 2$ expression was 100 times higher in MDAH cells. These findings suggest that $I P_{3} R 2$ may have an important role in MDAH/ DDP and MDAH cells in $\mathrm{Ca}^{2+}$ homeostasis influenced by iron.

While RYRs, a class of $\mathrm{Ca}^{2+}$ releasing channels, are rarely associated with cancer, they were reported to regulate proliferation of melanocytes and migration of T cells and astrocytes $[25,26]$. $R Y R 1$ is mainly expressed in skeletal muscle and although in small amounts, it is found in the heart muscle, smooth muscle, stomach, kidney, thymus, cerebellum, Purkinje cells, adrenal gland, testicle in the ovaries and B-lymphocytes [27]. $R Y R 2$ is mostly found in the heart muscle, while in small amounts, it is expressed in Purkinje cells, stomach, kidney, adrenal gland, ovary, thymus, and lung. RYR3 is expressed in hippocampal neurons, thalamus, Purkinje cells, corpus striatum, skeletal muscle, coronary smooth muscle cells, lung, kidney, ileum, jejunum. High conductivity RYR ion channels can form rapid transient increases of cytosolic $\mathrm{Ca}^{2+}$. Analysis of the primary structure of RYRs reveals various functional motifs seen in other proteins; however, the role of these motifs in the function of $R Y R$ has not been clarified yet [28]. In this study, an increase in gene expression levels of $R Y R 1$ was determined in iron treatment of MDAH and MDAH/DDP cells. In MDAH/DDP cells, there was no change in the effect of iron in the level of RYR2 mRNA, whereas in MDAH cells, the effect of iron was decreased. While differences in RYR2 mRNA gene expression levels are observed in MDAH cells, the absence of a significant change in MDAH/DDP cells indicates that RYR2 is not affected by iron concentrations. However, significant 
increase in RYR1 expression and subsequent reduction in increasing concentrations of iron in resistant MDAH cells showed that $R Y R 1$ can contribute to regulation of $\mathrm{Ca}^{2+}$ levels in resistant MDAH cells.

The SERCA pump is from the family of P-type ATPases and functions in intracellular calcium signal and homeostasis. SERCA has 3 isoforms. SERCA1/2 is expressed in some tissues, while SERCA3 is ubiquitous. Change in SERCA expression has been recorded in oral squamous cancer, choroid plexus, thyroid, lung, colon, acute promyelocytic leukemia, cervical and breast cancers [29-34]. During tumorigenesis in colon cancer, SERCA3 gene expression is gradually decreasing, while becoming almost zero in poorly differentiated tumors. Similarly, SERCA3 gene has not been expressed when compared to normal forms such as ductal carcinomas, acute promyelocytic leukemia cells and Burkitt lymphoma cells [33]. When SERCA1/2/3 mRNA gene expressions in iron effect were examined in cisplatin resistant MDAH/DDP cells, there was no change in SERCA1 and SERCA3 mRNA expressions, whereas SERCA2 mRNA gene expression was decreased. In iron treatment of MDAH cells, an increase in SERCA1/3 mRNA levels was determined, while the effect of iron was decreased in the level of SERCA2 mRNA. Changes in SERCA2 mRNA levels in cisplatin resistant cells under the influence of iron suggest that there may be a contribution to SERCA2 in the regulation of $\mathrm{Ca}^{2+}$ homeostasis in these cells. It also shows that changes in SERCA1/2/3 mRNA levels in MDAH cells under the influence of iron may play a role in regulating $\mathrm{Ca}^{2+}$ homeostasis in ovarian cancer epithelial cells.

There are 3 different isoforms of NCX proteins, NCX1, 2, and 3, that allow $\mathrm{Ca}^{2+}$ to be excreted from the plasma membrane. Pelzl et al. [35] showed that mRNA levels of $N C X 3$ in cisplatin resistant ovarian cells increased in relation to the sensitive cell line. Moreover, as a result of pre-incubation of cells with an NCX inhibitor KB-R7943, the inhibitor showed a blunted effect on $\left[\mathrm{Ca}^{2+}\right]_{i}$, and significantly augmented the cisplatin-induced cell death of cisplatin resistant ovary carcinoma cells without effecting cisplatin-induced cell death of cisplatin sensitive ovary carcinoma cells. In another study by Pelzl et al. [36], therapy sensitive D283, and therapy resistant UW228-3 medulloblastoma cells were used and they found that NCX3 silencing enhanced the apoptosis. In our study, we also found that NCX3 gene expression levels were increased in $\mathrm{MDAH} / \mathrm{DDP}$ cells at presence of iron. Our results support to previous studies and it is thought that NCX3 plays an important role in the drug resistance mechanism.

$P M C A$ is expressed ubiquitously, and has critical role for maintaining low resting ( $\left.\left[\mathrm{Ca}^{2+}\right] \mathrm{i}\right)$ in all eukaryotic cells. Cytotoxic $\mathrm{Ca}^{2+}$ overload has such a central role in cell death and the PMCA takes a role for the delicate balance between cell survival, and cell death. In general, the decreased $P M C A$ expression leads to cytotoxic $\mathrm{Ca}^{2+}$ overload and $\mathrm{Ca}^{2+}$ dependent cell death both in apoptosis and necrosis. Therefore, $P M C A$ is suggested to have a paradoxical role in cell survival in drug resistance. Our results also showed that the upregulation of PMCA1 at $10 \mu \mathrm{M}$, and $20 \mu \mathrm{M}$ iron and PMCA3 at $5 \mu \mathrm{M}, 40 \mu \mathrm{M}$ and $80 \mu \mathrm{M}$ in MDAH/DDP cells. Upregulation of PMCA1 and PMCA3 mRNA levels in cisplatin resistant EOCs under the influence of iron may suggest that PMCAs may be a separate pathway for resistant cells to escape from cell death and/or, perhaps a new route through which they efflux drugs out. In addition, some isoforms of $P M C A$ in colorectal and breast cancers have been shown to have significant changes in gene expression [37-42] and colorectal tumor tissues decreased PMCA4 compared to normal colon cancers.

Barabas and Faulk [43] have shown that doxorubicin-resistant human chronic myelogenous leukemia cells (K562) and promyelocytic leukemia cells (HL60) have up-regulated transferrin receptor (TfR) expression. They have also found that the number of transferrin receptors have been down-regulated by calcium channel blockers, such as verapamil, which is a well-known P-glycoprotein inhibitor and a calcium channel blocker. Doxorubicin-resistant HL60 cells did not overexpress P-glycoprotein, in comparison to drug-sensitive cells, by down regulating TfR. Davies et al. [44] have determined that TfR can be upregulated by growth hormones and this induction has been demonstrated to be triggered by calcium channels [45] and the blockade of such mechanism could re-sensitize drug-resistant cells [46]. This may explain the association of TfR with drug resistance through the function of calcium-sensitive receptors [37]. Finally, we may suggest in accordance with our results that there is a relation between calcium homeostasis and iron uptake and that this response is different in cisplatin-resistant cells than in cisplatin-sensitive cells. 
In conclusion, changes were observed in expression of $I P_{3} R 1, I P_{3} R 2, I P_{3} R 3, R Y R 1, R Y R 2, S E R C A 1$, and $S E R C A 3$ genes in iron treatment of MDAH cells, while changes were determined in $I P{ }_{3} R 2, R Y R 1, S E R C A 3, P M C A 1$, and PMCA2 gene expression in iron treatment of MDAH/DDP cells. These results suggest that changes in the expression of calcium channels, pumps and exchange proteins in the EOC cell line and cisplatin-resistant EOC cells may have an important role in iron regulation of calcium homeostasis. Due to the differences in gene expressions involved in regulation of calcium levels under the effect of iron, drug resistance can be prevented by introducing a new perspective on the use of inhibitors and activators of these genes and thus cytostatic treatment strategies.

\section{Abbreviations}

EOC: epithelial ovarian cancer

FAK: focal adhesion kinase

$I P_{3} R s$ : inositol 1,4,5-triphosphate receptors

MTT: 3-(4,5-dimethylthiazol-2-yl)-2,5-diphenyltetrazolium bromide

NCX: $\mathrm{Na}^{+} / \mathrm{Ca}^{2+}$ exchange

PMCA: plasma membrane $\mathrm{Ca}^{2+}$ ATPase

ROS: reactive oxygen species

RT-PCR: reverse transcription-polymerase chain reaction

RYRs: ryanodine receptors

SERCA: sarco/endoplasmic reticulum $\mathrm{Ca}^{2+}$ ATPase

TfR: transferrin receptor

\section{Declarations}

\section{Acknowledgements}

We would like to thank Mr. Ali Öztürk for them support in this study.

\section{Author contributions}

LY, BK, and DE contributed conception and design of the study; LY, DE, and FA organized the database; LY performed the statistical analysis; BK wrote the first draft of the manuscript; and LY, BK and DE wrote sections of the manuscript. All authors contributed to manuscript revision, read and approved the submitted version.

\section{Conflicts of interest}

Regarding this study, the authors and/or family members have no scientific or medical committee membership or relationship with their members, counseling, expertise, employment status in any company, shareholding, and similar situations.

\section{Ethical approval}

Not applicable.

\section{Consent to participate}

Not applicable.

\section{Consent to publication}

Not applicable.

\section{Availability of data and materials}

Not applicable. 


\section{Funding}

This work was supported by Istanbul University Scientific Research Projects Coordination Unit. Project number: TSA-2017-24579. The funder had no role in study design, data collection and analysis, decision to publish, or preparation of the manuscript.

\section{Copyright}

(C) The Author(s) 2021.

\section{References}

1. Büsselberg D, Florea AM. Targeting intracellular calcium signaling $\left(\left[\mathrm{Ca}^{2+}\right]_{\mathrm{i}}\right)$ to overcome acquired multidrug resistance of cancer cells: a mini-overview. Cancers (Basel). 2017;9:48.

2. Kazan HH, Urfali-Mamatoglu C, Gunduz U. Iron metabolism and drug resistance in cancer. Biometals. 2017:30;629-41.

3. Xu L, Xie Q, Qi L, Wang C, Xu N, Liu W, et al. Bcl-2 overexpression reduces cisplatin cytotoxicity by decreasing ER-mitochondrial $\mathrm{Ca}^{2+}$ signaling in SKOV3 cells. Oncol Rep. 2018;39:985-92.

4. Kouba S, Ouldamer L, Garcia C, Fontaine D, Chantome A, Vandier C, et al. Lipid metabolism and calcium signaling in epithelial ovarian cancer. Cell Calcium. 2019;5:38-50.

5. Cui C, Merritt R, Fu L, Pan Z. Targeting calcium signaling in cancer therapy. Acta Pharm Sin B. 2017;7:3-17.

6. Santulli G, Nakashima R, Yuan Q Marks AR. Intracellular calcium release channels: an update. J Physiol. 2017;595:3041-51.

7. Lencesova L, Krizanova O. IP 3 receptors, stress and apoptosis. Gen Physiol Biophys. 2012;31:119-30.

8. Hegedũs L, Garay T, Molnár E, Varga K, Bilecz Á, Török S, et al. The plasma membrane $\mathrm{Ca}^{2+}$ pump PMCA4b inhibits the migratory and metastatic activity of BRAF mutant melanoma cells. Int J Cancer. 2017;140:2758-70.

9. Fodor J, Gombo-Toth A, Olah T, Zador E, Toht ZC, Ioannis I, et al. Alteration of sarcoplasmic reticulum $\mathrm{Ca}^{2+}$ ATPase expression in lower limb ischemia caused by atherosclerosis obliterans. Physiol Int. 2017;104:183-92.

10. Marques O, da Silva BM, Porto G, Lopes C. Iron homeostasis in breast cancer. Cancer Lett. 2014;347:1-14.

11. Kucukkaya B, Basoglu H, Erdag D, Akbas F, Susgun S, Yalcintepe L. Calcium homeostasis in cisplatin resistant epithelial ovarian cancer. Gen Physiol Biophys. 2019;38:353-63.

12. Prencipe M, Fitzpatrick P, Gorman S, Tosetto M, Klinger R, Furlong F, et al. Cellular senescence induced by aberrant MAD2 levels impacts on paclitaxel responsiveness in vitro. Br J Cancer. 2009;101:1900-8.

13. Schmittgen TD, Livak KJ. Analyzing real-time PCR data by the comparative $\mathrm{C}_{\mathrm{T}}$ method. Nat Protoc. 2008;3:1101-8.

14. Dasari S, Tchounwou PB. Cisplatin in cancer therapy: molecular mechanisms of action. Eur J Pharmacol. 2014;740:364-78.

15. Dulhunty AF, Beard NA, Casarotto MG. Recent advances in understanding the ryanodine receptor calcium release channels and their role in calcium signaling. F1000Res. 2018;7:F1000 Faculty Rev-1851.

16. Humeau J, Bravo-San Pedro JM, Vitale I, Nunez L, Villalobos C, Kroemer G, et al. Calcium signaling and cell cycle: progression or death. Cell Calcium. 2017;70:3-15.

17. Kahl CR, Means AR. Calcineurin regulates cyclin D1 accumulation in growth-stimulated fibroblasts. Mol Biol Cell. 2004;15:1833-42.

18. Prevarskaya N, Ouadid-Ahidouch H, Skryma R, Shuba Y. Remodelling of $\mathrm{Ca}^{2+}$ transport in cancer: how it contributes to cancer hallmarks? Philos Trans R Soc Lond B Biol Sci. 2014;369:20130097. 
19. Bouchard V, Demers MJ, Thibodeau S, Laquerre V, Fujita N, et al. Fak/Src signaling in human intestinal epithelial cell survival and anoikis: differentiation state-specific uncoupling with the PI3-K/Akt-1 and MEK/Erk pathways. J Cell Physiol. 2007;212:717-28.

20. Giannone G, Ronde P, Gaire M, Beaudouin J, Haiech J, Ellenberg J, et al. Calcium rises locally trigger focal adhesion disassembly and enhance residency of focal adhesion kinase at focal adhesions. J Biol Chem. 2004;279:28715-23.

21. Tai YL, Chen LC, Shen TL. Emerging roles of focal adhesion kinase in cancer. Biomed Res Int. 2015;2015:690690.

22. Brini M, Carafoli E. Calcium pumps in health and disease. Physiol Rev. 2009;89:1341-78.

23. Foskett JK, White $\mathrm{C}$, Cheung $\mathrm{KH}, \mathrm{Mak}$ DO. Inositol trisphosphate receptor $\mathrm{Ca}^{2+}$ release channels. Physiol Rev. 2007;87:593-658.

24. Miyakawa T, Maeda A, Yamazawa T, Hirose K, Kurosaki T, Iino M. Encoding of $\mathrm{Ca}^{2+}$ signals by differential expression of IP $_{3}$ receptor subtypes. EMBO J. 1999;18:1303-8.

25. Bustos G, Cruz P, Lovy A, Cárdenas C. Endoplasmic reticulum-mitochondria calcium communication and the regulation of mitochondrial metabolism in cancer: a novel potential target. Front Oncol. 2017;8:199.

26. Kang HY, Kim NS, Lee CO, Lee JY, Kang WH. Expression and function of ryanodine receptors in human melanocytes. J Cell Physiol. 2000;185:200-6.

27. Lanner JT, Georgiou DK, Joshi AD, Hamilton SL. Ryanodine receptors: structure, expression, molecular details, and function in calcium release. Cold Spring Harb Perspect Biol. 2010;2:a003996.

28. Hamilton SL, Serysheva II. Ryanodine receptor structure: progress and challenges. J Biol Chem. 2009;284:4047-51.

29. Endo Y, Uzawa K, Mochida Y, Shiiba M, Bukawa H, Yokoe $\mathrm{H}$, et al. Sarcoendoplasmic reticulum $\mathrm{Ca}^{2+}$ ATPase type 2 downregulated in human oral squamous cell carcinoma. Int J Cancer. 2004;110:225-31.

30. Pacifico F, Ulianich L, De Micheli S, Treglia S, Leonardi A, Vito P, et al. The expression of the sarco/ endoplasmic reticulum $\mathrm{Ca}^{2+}$-ATPases in thyroid and its down-regulation following neoplastic transformation. J Mol Endocrinol. 2003;30:399-409.

31. Bergner A, Kellner J, Tufman A, Huber RM. Endoplasmic reticulum $\mathrm{Ca}^{2+}$-homeostasis is altered in Small and non-small Cell Lung Cancer cell lines. J Exp Clinical Cancer Res. 2009;28:25.

32. Chung FY, Lin SR, Lu CY, Yeh CS, Chen FM, Huang TJ, et al. Sarco/endoplasmic reticulum calcium-ATPase 2 expression as a tumor marker in colorectal cancer. Am J Surg Pathol. 2006;30:969-74.

33. Arbabian A, Brouland JP, Gelebart $\mathrm{P}$, Kovàcs T, Bobe R, Enouf J, et al. Endoplasmic reticulum calcium pumps and cancer. BioFactors. 2011;37:139-49.

34. Li W, Ouyang Z, Zhang Q, Wang L, Shen Y, Wu X, et al. SBF-1 exerts strong anticervical cancer effect through inducing endoplasmic reticulum stress-associated cell death via targeting sarco/endoplasmic reticulum $\mathrm{Ca}^{2+}$-ATPase 2. Cell Death Dis. 2014;5:e1581.

35. Pelzl L, Hosseinzadeh Z, Alzoubi K, Al-Maghout T, Schmidt S, Stournaras C, et al. Impact of $\mathrm{Na}^{+} / \mathrm{Ca}^{2+}$ exchangers on therapy resistance of ovary carcinoma cells. Cell Physiol Biochem. 2015;37:1857-68.

36. Pelzl L, Hosseinzadeh Z, Al-Maghout T, Singh Y, Sahu I, Bissinger R, et al. Role of $\mathrm{Na}^{+} / \mathrm{Ca}^{2+}$ exchangers in therapy resistance of medulloblastoma cells. Cell Physiol Biochem. 2017;42:1240-51.

37. Papp B, Brouland JP. Altered endoplasmic reticulum calcium pump expression during breast tumorigenesis. Breast Cancer (Auckl). 2011;5:163-74.

38. Aung CS, Ye W, Plowman G, Peters AA, Monteith GR, Roberts-Thomson SJ. Plasma membrane calcium ATPase 4 and the remodeling of calcium homeostasis in human colon cancer cells. Carcinogenesis. 2009;30:1962-9. 
39. Ribiczey P, Tordai A, Andrikovics H, Filoteo AG, Penniston JT, Enouf J, et al. Isoform-specific up-regulation of plasma membrane $\mathrm{Ca}^{2+}$ ATPase expression during colon and gastric cancer cell differentiation. Cell Calcium. 2007;42:590-605.

40. Curry MC, Luk NA, Kenny PA, Roberts-Thomson SJ, Monteith GR. Distinct regulation of cytoplasmic calcium signals and cell death pathways by different plasma membrane calcium ATPase isoforms in MDA-MB-231 breast cancer cells. J Biol Chem. 2012;287:28598-608.

41. Varga K, Pászty K, Padányi R, Hegedűs L, Brouland JP, Papp B, et al. Histone deacetylase inhibitor- and PMA-induced upregulation of PMCA4b enhances $\mathrm{Ca}^{2+}$ clearance from MCF-7 breast cancer cells. Cell Calcium. 2014;55:78-92.

42. Rüschoff JH, Brandenburger T, Strehler EE, Filoteo AG, Heinmöller E, Aumüller G, et al. Plasma membrane calcium ATPase expression in human colon multistep carcinogenesis. Cancer Invest. 2012;30:251-7.

43. Barabas K, Faulk WP. Transferrin receptors associate with drug resistance in cancer cells. Biochem Biophys Res Commun. 1993;197:702-8.

44. Davies PS, Zhang AS, Anderson EL, Roy CN, Lampson MA, McGraw TE, et al. Evidence for the interaction of the hereditary haemochromatosis protein, HFE, with the transferrin receptor in endocytic compartments. Biochem J. 2003;373:145-53.

45. Necker LM. Regulation of transferrin receptor expression and control of cell growth. Pathobiology. 1991;59:11-8.

46. Cornwell MM, Pastan I, Gottesman MM. Certain calcium channel blockers bind specifically to multidrugresistant human $\mathrm{KB}$ carcinoma membrane vesicles and inhibit drug binding to P-glycoprotein. J Biol Chem. 1987;262:2166-70. 